\title{
Verbal and visual training in face recognition*
}

\author{
ROY S. MALPASS, HENRY LAVIGUEUR $†$, and DAVID E. WELDON \\ University of Illinois, Champaign-Urbana, Champaign, Illinois 61820
}

\begin{abstract}
Black and white $\mathrm{Ss}$ were given recognition training for black and white faces. One experiment asked black and white Ss to describe black or white faces verbally, to recognize faces from verbal descriptions, and to describe similarities and differences in triads of faces. While verbal training did affect verbal usage and verbal recognition performance, there was no indication, either before or after training, of verbal usage or performance patterns which parallel visual recognition performance. Black Ss yielded higher recognition scores for black faces than for white; white Ss yielded higher recognition scores for white faces than for black. The second experiment trained white Ss for recognition of black or white faces by feedback trials, using a four-alternative forced-choice procedure. The initial difference in performance for white and black faces ( $W>B$ ) was not present after 100 training trials. Results are related to an earlier study of face recognition by Malpass and Kravitz (1969).
\end{abstract}

Differential recognition performance by persons of one social group for members of another has been documented by Malpass and Kravitz (1969) and by Cross, Cross, and Daly (1971).

The phenomenon has both social and theoretical import. To the extent that whites or blacks have more difficulty in accurately recognizing persons of the other race, ${ }^{1}$ policemen and witnesses to crimes will be less efficient in the identification of offenders of race other than their own. Equally important is the complement of this inefficiency: the likelihood of an innocent person being wrongly identified as the offender increases with the differential in recognition performance. This kind of discrimination, even if not volitional, can only exacerbate existing social inequities.

There is very little work directly on recognition of faces, and the recent work indicates that processing of faces in memory is not well understood. The content (images, verbal labels) and form (feature lists, schemas, templates) of memory for faces are not known. For some experimental tasks (same/different judgments, Smith \& Nielson, 1970) storage may be visual in content, at least in short-term memory. For long-term memory, the form and content of memory for photographs may depend on the nature of the anticipated experimental task (Tversky, 1969). Frost (1970) concludes that pictures are encoded differentially, depending on task expectation, and that if there is a single form and content of storage in long-term memory both visual and verbal access are possible. Simple storage of information about facial features cannot alone account for face recognition performance,

*This research was supported by the Research Board of the University of Illinois and in part by Grant No. MH 18204 from the National Institute of Mental Health. The authors would like to thank Allan Wicker and Larry Jones for their comments on an earlier version of the manuscript. Requests for reprints should be sent to Roy S. Malpass, Department of Psychology, University of Illinois, Champaign, Illinois 61820.

tThe second experiment reported here is based on investigations carried out by the second author under the direction of the first author, and submitted to the Graduate College, University of Illinois, in partial fulfillment for the MA degree in psychology. since when faces are presented in photographic negative (thus preserving feature relationships) recognition suffers (Galper, 1970; Galper \& Hochberg, 1971). Similarly, Yin (1969) and Hochberg and Galper (1967) find that recognition of faces is more adversely affected by inversion than is the case for other complex objects.

Few studies have specifically investigated verbal aspects of face recognition. Goldstein and Chance (1970) found negative, but small, correlations between the number of identifying associations given a stimulus face and its recognizability, but other stimulus objects showed varying relations with verbal association: Inkblots showed a positive relation, while snow crystals showed a negative relation. Other work has been done on the relation of recognizability of objects and verbal coding of those objects. Brown and Lenneberg (1954) developed the concept of the codability of an object, operationalized as intersubjective agreement on the labeling of an object. They found the codability of color chips related to their recognizability. Using a similar approach, Frijda and Van de Geer (1961) found a codability-recognizability relation for facial expressions. Lantz and Stefflre (1964) refined the codability concept, indexing the degree to which Ss reliably code objects verbally and are then able to "recognize" the object on the basis of the verbal code. This index was called communication accuracy, and it was found to be more generally related to recognizability than was codability. The work on communication accuracy assumes that recognition is essentially a problem of communicating the important attributes of a stimulus object to one's self for future use, and that important aspects of this communication are in verbal form. The measurement of communication accuracy assumes that in a linguistically homogeneous group intersubjective communication accuracy is a good index of intrasubjective communication accuracy and should therefore correlate with visual recognizability of objects.

Assuming more frequent and important experience with members of one's own race, verbal reference should become specialized to communicating information accurately about faces of one's own race, to the extent that characteristics of faces differ from one group to 
another. ${ }^{2}$ Some evidence on this point is given by Palmer and Masling (1969), who showed that the relative vocabularies of black children for skin color were greater than those of white children.

If properties of verbal usage for faces, especially communication accuracy, are related to visual recognition because verbal processes are important in the storage and processing of information about faces, differential verbal usage for faces should appear to the degree that groups exhibit differential face recognition. Further, training in communication accuracy should affect both communication accuracy and face recognition.

\section{EXPERIMENT I}

Experiment I was undertaken to examine two propositions: (1) The pattern (data plots) of a number of aspects of verbal usage, including communication accuracy, roughly parallels the pattern of differential face recognition. An interaction between race of $S$ s and race of stimulus face is expected such that references to faces of one's own race are more specific, more differentiated (complex), and display greater communication accuracy. (2) Training in describing faces verbally will result in changes in verbat usage that in turn result in improved face recognition. An interaction is expected showing that verbal training with respect to one's own group will be relatively ineffective as compared with the other group.

\section{Method}

\section{Subjects}

Sixty-one black and 67 white Ss, all students at the University of Illinois and all experimentally naive, were paid for their participation.

\section{Training Stimuli}

Photographs, between 1 and $3 \mathrm{in}$. high, of young males, 90 black and 90 white, were cut from a variety of magazines and catalogues and were pasted on $4 \times 6$ in. index cards.

\section{Training Procedure}

Four levels of training were investigated, using four randomly constructed independent groups of $\mathrm{Ss}$ (eight, four and two sessions, and no training), each comprising four subgroups representing the four race of $S /$ race of training stimulus combinations. Training occurred in group sessions of $1 \mathrm{~h}$ duration. The interval between sessions varied unsystematically between 4 and 7 days. There was no explicit or intentional manipulation of incentive for increasing recognition accuracy.

The Ss of each race were assigned Jasdomly to receive training on white or on black faces, with the restriction that one-half of each racial group receive training on own-race faces, the other half on other-race faces Three training tasks were performed during each training session: description of faces, recognition of faces from verbal descriptions of the face (not included in first session), and a triadic comparison task.

Description of faces. Ss were instructed to describe stimulus faces so that a friend could correctly identify the face from a group of others on the basis of the description alone, but not to refer to objects of clothing and not to report inferences based on facial features, such as personality traits. From 12 to 18 descriptions were written during a session. This number varied unsystematically. Stimulus faces were sampled randomly from the total of 90 for each training session. From these descriptions, two measures of verbal usage were taken for each $S$ : the average number of references to global facial features per face, such as "smile," "fat face," and the average number of references to specific facial features per face, such as lip color or eyebrow shape.

Recognition from verbal description. Composite descriptions were constructed using any cue given by five or more $S s$ in the previous week's training. The actual number of such cues varied unsystematically between 8 and 12 . The descriptions were accompanied by the correct face and one other, the face whose descriptions were most similar to the correct face in the previous training session for that group. The number of two-alternative forced-choice judgments in a given session varied from six to nine, but was always six in the last training session, from which the measurements analyzed below were taken. The order of presentation was randomized, and $S s$ were given $15 \mathrm{sec}$ for each choice. The number of faces correctly recognized, out of six presented in the last training session, was the measure of communication accuracy.

Triadic comparison task. Ss were instructed to record which two of three faces were the most similar, how they were similar, and the way in which these two were different from the third. From these responses, three indices of the complexity of judgments were derived: the number of unique physiognomic attributes given for similarity and for different judgments, and the average number of attributes given per triad.

\section{Measurement of Physiognomic Recognition}

The recognition task and the stimulus faces employed are described fully by Malpass and Kravitz (1969). The faces were sampled from a pool of photographs of white and of black college age men wearing similar white " $T$ " shirts, facing the camera position, with "neutral" facial expression. The inspection series was made up of 10 black and 10 white faces, which were shown for $1 \mathrm{sec}$ each with an interstimulus interval of $1 \mathrm{sec}$. After a $1-m i n$ interval, Ss were shown a recognition series composed of the 10 black stimuli previously shown plus 30 unfamiliar black photographs intermixed with the 10 white stimuli previously shown plus 30 unfamiliar white photographs. The 80 photographs in the recognition series were shown for 4 sec each, during which time $S s$ were to indicate whether or not they had seen each face in the first sequence by circling "yes" or "no" on a response sheet. Ss were seated at distances varying from 8 to $12 \mathrm{ft}$ from a matte white screen, in no case being displaced from the axis perpendicular to the image by more than $6 \mathrm{ft}$. Projected image size was approximately $24 \times 36$ in. Four mutually exclusive randomly selected sets of inspection faces were used. These were counterbalanced across Ss within conditions. The recognition series was organized by 20 blocks of four faces such that one member of each of the four mutually exclusive inspection sets appeared in each block. Thus, the same recognition series was used for all four sets of inspection faces. The block in which a given face appeared in the recognition series, its position in the block, and its position in the inspection series were determined randomly, with the restriction that no more than three faces of given race appear in sequence. The recognition measure was taken after the last training session. 
Table 1

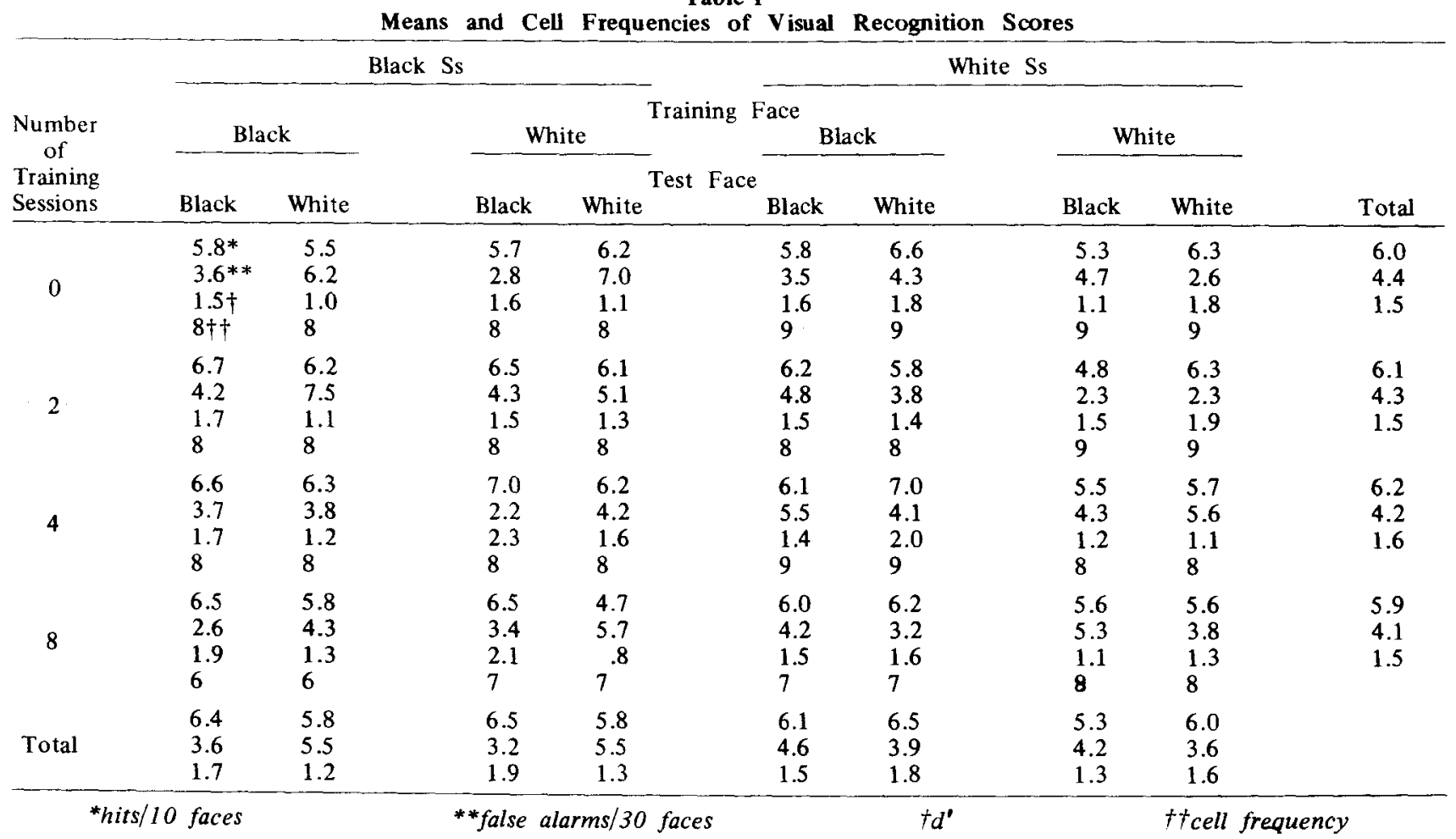

\section{Results}

\section{Visual Recognition}

Recognition accuracy. Two scores were obtained from Ss' recognition performance, number of correct identifications (hits) and number of false identifications (false alarms). From these, the index $d^{\prime}$, derived by the theory of signal detectability (TSD), is obtained. TSD is discussed in the context of recognition memory by Banks (1970). d' is a measure of discriminability of a stimulus or of the recognition acuity of the $S$, the two being confounded where" stimulus strength measurements are not available. Values of $\mathrm{d}^{\prime}$ were obtained from tables given by Elliott (1964), which assume that the underlying distributions of old and new events are distributed normally and have equal variance. Means of hits, false alarms, and $d^{\prime}$ are presented in Table 1. These three scores were submitted separately to a four-factor unweighted means analysis of variance (Race of $\mathrm{S}$ by Race of Training Stimulus by Amount of Training by Race of Test Stimulus) with one repeated measure (Race of Test Stimulus), summarized in Table 2. An unweighted means analysis was done because of unequal cell sizes resulting from some Ss' failing to attend all training sessions of their groups.

The interaction of Race of $\mathbf{S}$ by Race of Test Stimulus was significant for hits, false alarms, and for $\mathrm{d}^{\prime}$, and is presented in Fig. 1. Tests of the simple main effects on $d^{\prime}$ of race of $S$ within levels of race of stimulus show superior recognition $\left(d^{\prime}\right)$ of faces of own race $(F=11.78$ and 9.32 for black and for white faces, respectively, $\mathrm{df}=$

Table 2

Significant Factors in Analysis of Variance of Hits, False Alarms, and $d^{\prime}$ in a Visual Recognition Task (F Ratios Above 2.0 are Entered)

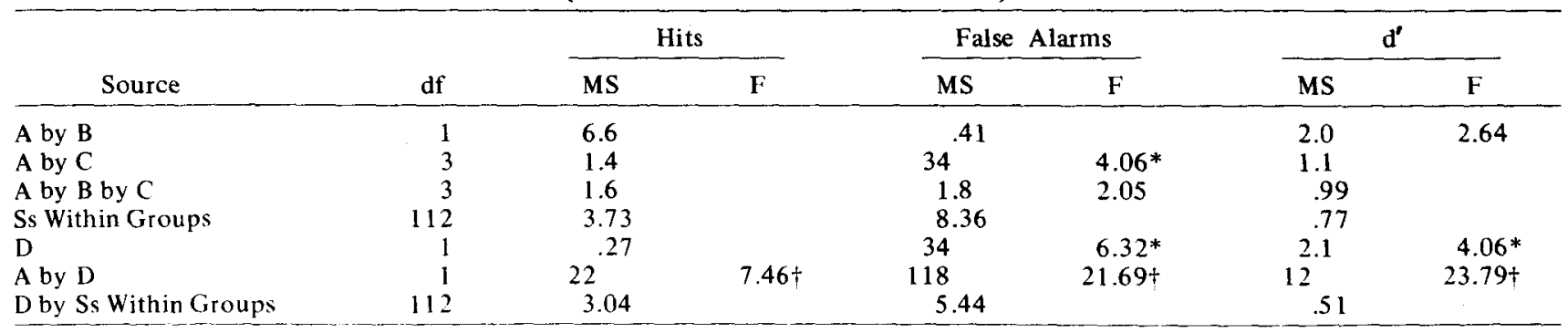

$*_{p}<.05 \quad$ Iariables and dfs: A (race of $\left.S .1\right) . B$ (race of training stimulus. $l$ ). $C$ (number of training sessions, 3). $D$ (race of test stimulus. 1). Repeated-measure's design with one repeated measure (D). 


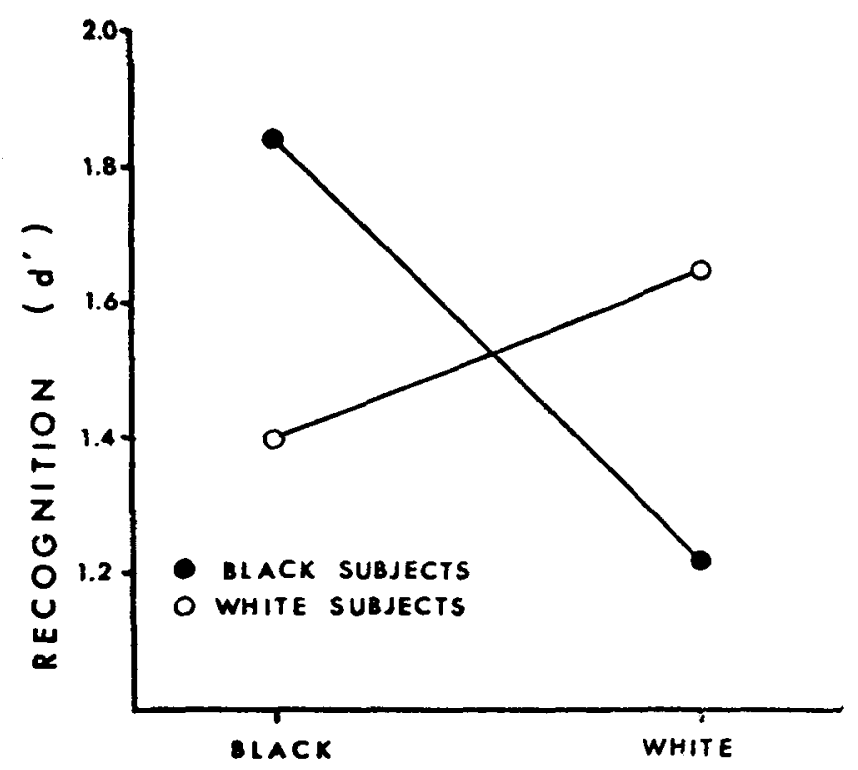

FACES

Fig. 1. Interaction of Race of $S$ by Race of Face on d'.

$1,112, p<.01)$. Tests of the simple main effects of race of stimulus within levels of race of $S$ show superior recognition ( $d$ ') of black faces as compared with white faces by black Ss $(F=25.15$, df $=1,112, p<.01)$ and superior recognition $\left(d^{\prime}\right)$ of white faces as compared with black faces by white Ss $(F=4.43$, df $=1,112$, $\mathrm{p}<.05$ ).

The main effect on $d^{\prime}$ scores for race of test stimulus is significant, but the means are in the direction opposite to the Malpass and Kravitz (1969) findings: black faces were better recognized on the average than white faces $\left[\overline{\mathrm{X}}\left(\mathrm{d}^{\prime}\right) 1.62>1.44\right]$.

For false alarms, the interaction of Race of $S$ by Race of Test Stimulus indicates a general tendency for Ss to give more false alarms to faces of other race. The significant main effect for false alarms showed more false alarms given, in general, to black stimuli.

Verbal usage. A four-factor independent groups unweighted means analysis of variance was performed separately on each of the six measures of verbal usage described above. Race of $S$, sex of $S$, race of training faces, and number of training sessions were classification factors. Data were obtained from the Ss' performance using the training stimuli during the last training session of the 2-, 4-, and 8-week training groups (Table 3).

Statistically significant effects were: Verbal usage was differential by sex of $S$ in average number of specific descriptions (female $>$ male); average number of responses per triad (female $>$ male); and complexity of "same" descriptions (male $>$ female). Responses were differential for race of the stimulus face for the number of global descriptions (white $>$ black), average number of responses per triad (black $>$ white), and for complexity of both "same" and "different" descriptions (white $>$ black). As noted in Table 3, only 1 of the 11 interaction effects on six dependent variables attained statistical significance.

\section{Training}

Training produced significant changes in average number of responses per triad (decreasing over training), complexity of "different" judgments (increasing over training), and verbal recognition (increasing with training).

\section{Discussion}

\section{Replication of Previous Findings}

The interaction of Race of $S$ by Race of Stimulus Face (Fig. 1) shows a pattern different from that obtained by Malpass and Kravitz (1969). They found recognition of black Ss for black faces and for white faces to be very similar, while white Ss' recognition scores were polarized (W > B). Comparison of the two studies is confounded by intervening events on the campus which polarized black and white student populations, and which may have influenced the type of black Ss volunteering for psychology experiments. However, a more specific interpretation concerns

Table 3

Independent Groups Analysis of Variance of Dependent Measures Derived from Three Training Tasks (F Ratios Above 2.0 are Entered)

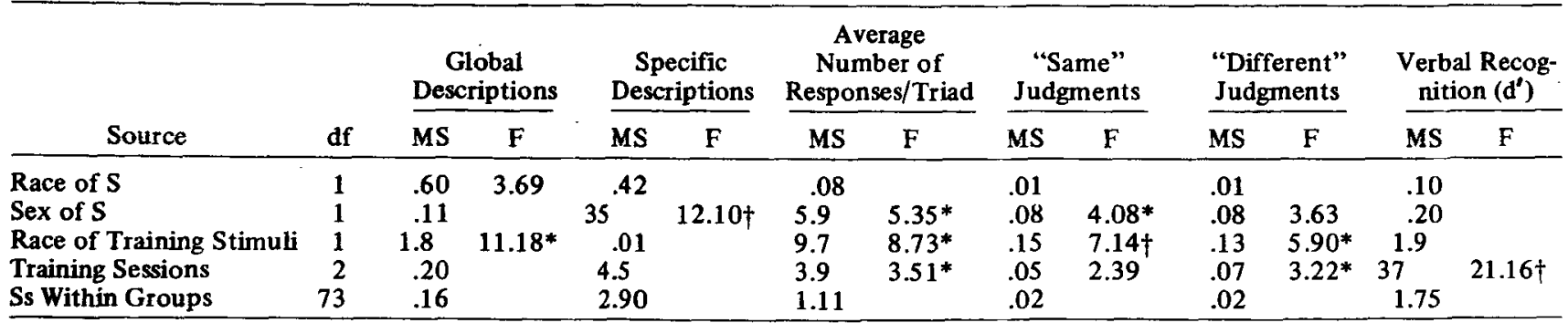

Note-Due to unequal cell frequencies, an unweighted means analysis was performed. Interactions are omitted. One $(B$ by $C$ by $D$, "different" judgments) was significant at $\alpha<.001 . \quad{ }^{*} p<.01 \quad$ tp $<.001$ 
differences in average discriminability of the samples of photographs used as stimuli in the two studies. Shifting the level of recognition for black faces upwards, the recognition for white faces downwards, or both, would produce the change in main effect pattern reported as well as the different pattern of the interaction described above. Stimulus scaling data are required to evaluate this interpretation definitely, but are not yet available for these faces.

\section{Patterns of Verbal Usage and Effects of Verbal Training}

An interaction of Race of $S$ by Race of Stimulus Face did not appear for any of the measures of verbal usage (Table 3). The $\mathrm{F}$ ratios for this effect were in general less than 1 . None of the verbal usage variables examined in the present study showed a pattern of use similar to the differential recognition findings, contrary to expectation.

Verbal training did have the anticipated effect on three verbal usage variables, including communication accuracy, but no effect of training on visual recognition was evident. Note, however, that the form of the inspection information (verbal or visual) was not the only difference between the verbal training and the visual recognition tasks. The verbal tasks used photographs of faces in nonstandard pose with nonstandard facial expression, whereas the visual recognition task used a different set of faces, standardized in pose and expression. This difference in materials would work against a transfer effect.

Since our purpose was to detect any verbal usage patterns present that paralleled the visual recognition pattern, a canonical correlation analysis was performed to explore relations among a number of independent variables, dependent variables, and their interrelations, including a number of interesting interactions among independent variables and covariates such as standardized verbal and quantitative ability measures. Two significant roots were obtained. The first root was clearly interpretable as reflecting the training effects shown in the analysis of variance. The second yielded very much the same orders of importance of relations among sets of variables as found in the other effects in the analysis of variance. No interpretable pattern of relation of verbal usage variables with visual recognition was evident. ${ }^{3}$

In view of these findings, an experimental study of visual training was undertaken.

\section{EXPERIMENT II}

This experiment examined white $\mathrm{Ss}^{\prime}$ recognition performance over the course of training, using either white or black faces within a visual recognition training task and providing performance-contingent outcomes of two types (electric shock and verbal statement of wrong/correct) in addition to a no-feedback control condition.

The stimulus pool from which faces in this experiment were sampled totaled 100 black and 100 white faces. The faces used by Malpass and Kravitz and in Experiment $I$ above are included in this total. To test hypotheses about training, it is necessary to provide sufficient training to reasonably expect an effect. In order to provide training of sufficient length to be worthwhile, it was necessary to use each of the 100 faces more than once. Reusing the faces should be expected to result in interference effects in the recognition task, since some of the distractor faces in the four-alternative forced-choice tasks employed will have been seen earlier, either as distractors or as faces to be recognized. The position of each white and black face in the respective inspection and recognition series was determined semirandomly, as described below. Thus, conditions of interference from sampling faces with replacement for the recognition series were the same for the two sets of faces. Without relevant data from recognition tasks, we can anticipate that the effects of interference will either operate equally on black and white faces or affect the more difficult faces more (black faces for white Ss).

As a result, if training in the present study is ineffective, we would expect the course of accuracy in face recognition for black and for white faces either to be parallel or to diverge, with recognition for black faces being the worse. If training in face recognition is effective, irrespective of differential effectiveness of training, we would expect the levels of recognition accuracy to improve after some degree of training. Considering differential effects of training, we could anticipate at least two alternative outcomes. First, that training will be the more effective with the initially "easier" (white) faces, and that recognition accuracy for black and for white faces will diverge over training. This result would not be distinguishable from the differential effect of interference on materials of varying difficulty. Second, there may be a ceiling effect on recognition accuracy under the experimental conditions, which if it occurred at the same absolute level of recognition accuracy for the two sets of faces would produce an eventual convergence of accuracy for recognizing black and white faces. Initial performance should favor white faces. Shock avoidance training is expected to be superior to nonshock information feedback, and both should be superior to no feedback.

\section{Method}

\section{Subjects}

One hundred white male undergraduate students from the introductory psychology course at the University of Illinois received course credit for their participation in the experiment.

\section{Training Faces}

The training faces were taken from an expanded set of 
Table 4

Means of Correct Response and $d^{\prime}$ Scores

\begin{tabular}{|c|c|c|c|c|c|c|c|}
\hline & \multicolumn{6}{|c|}{ Training Block } & \multirow[b]{2}{*}{$\mathrm{CF}+\dagger$} \\
\hline & 1 & 2 & 3 & 4 & 5 & Total & \\
\hline $\begin{array}{l}\text { Black Face } \\
\text { Non- } \\
\text { Feedback }\end{array}$ & $\begin{array}{l}2.25^{*} \\
.860^{*}\end{array}$ & $\begin{array}{r}1.81 \\
* .760\end{array}$ & $\begin{array}{l}1.60 \\
.730\end{array}$ & $\begin{array}{l}1.79 \\
.743\end{array}$ & $\begin{array}{l}2.09 \\
.810\end{array}$ & $\begin{array}{l}1.91 \\
.780\end{array}$ & 15 \\
\hline $\begin{array}{l}\text { Verbal } \\
\text { Feedback }\end{array}$ & $\begin{array}{l}2.16 \\
.843\end{array}$ & $\begin{array}{l}2.05 \\
.833\end{array}$ & $\begin{array}{l}1.63 \\
.730\end{array}$ & $\begin{array}{l}1.69 \\
.753\end{array}$ & $\begin{array}{l}2.14 \\
.833\end{array}$ & $\begin{array}{l}1.93 \\
.798\end{array}$ & 15 \\
\hline $\begin{array}{l}\text { Shock } \\
\text { Feedback }\end{array}$ & $\begin{array}{l}2.41 \\
.898\end{array}$ & $\begin{array}{l}2.19 \\
.823\end{array}$ & $\begin{array}{l}2.12 \\
.840\end{array}$ & $\begin{array}{l}2.18 \\
.835\end{array}$ & $\begin{array}{l}2.64 \\
.910\end{array}$ & $\begin{array}{l}2.31 \\
.859\end{array}$ & 20 \\
\hline Total & $\begin{array}{l}2.30 \\
.866 \\
1.80 \dagger\end{array}$ & $\begin{array}{l}2.03 \\
.807 \\
2.64\end{array}$ & $\begin{array}{l}1.82 \\
.774 \\
2.57\end{array}$ & $\begin{array}{l}1.92 \\
.783 \\
3.03\end{array}$ & $\begin{array}{l}2.33 \\
.857 \\
2.46\end{array}$ & & \\
\hline $\begin{array}{l}\text { White Face } \\
\text { Non- } \\
\text { Feedback }\end{array}$ & $\begin{array}{l}2.37 \\
.883\end{array}$ & $\begin{array}{l}1.85 \\
.777\end{array}$ & $\begin{array}{l}1.84 \\
.787\end{array}$ & $\begin{array}{l}2.20 \\
.813\end{array}$ & $\begin{array}{l}1.92 \\
.800\end{array}$ & $\begin{array}{l}2.04 \\
.812\end{array}$ & 15 \\
\hline $\begin{array}{l}\text { Verbal } \\
\text { Feedback }\end{array}$ & $\begin{array}{l}2.68 \\
.917\end{array}$ & $\begin{array}{l}2.23 \\
.863\end{array}$ & $\begin{array}{l}2.30 \\
.867\end{array}$ & $\begin{array}{l}2.36 \\
.910\end{array}$ & $\begin{array}{l}2.19 \\
.820\end{array}$ & $\begin{array}{l}2.35 \\
.875\end{array}$ & 15 \\
\hline $\begin{array}{l}\text { Shock } \\
\text { Feedback }\end{array}$ & $\begin{array}{l}2.76 \\
.930\end{array}$ & $\begin{array}{r}2.28 \\
.850\end{array}$ & $\begin{array}{l}1.96 \\
.793\end{array}$ & $\begin{array}{l}2.49 \\
.878\end{array}$ & $\begin{array}{l}2.25 \\
.850\end{array}$ & $\begin{array}{l}2.35 \\
.860\end{array}$ & 20 \\
\hline Total & $\begin{array}{l}2.62 \\
.912 \\
1.53 \dagger \\
\end{array}$ & $\begin{array}{l}2.14 \\
.832 \\
2.67 \\
\end{array}$ & $\begin{array}{l}2.03 \\
.813 \\
2.70 \\
\end{array}$ & $\begin{array}{l}2.36 \\
.865 \\
2.04 \\
\end{array}$ & $\begin{array}{l}2.13 \\
.826 \\
2.50 \\
\end{array}$ & & \\
\hline
\end{tabular}

*d' *correct responses/20 tSD of correct responses within training blocks, without regard to feedback type t†cell frequency

photographs taken following the same procedures as used by Malpass and Kravitz (1969). The expanded set contained the faces used for measuring recognition performance in Experiment I above.

\section{Treatments}

Two treatment variables were manipulated: the race of the training faces and the type of recognition performance feedback (no feedback, verbal feedback, electric shock feedback). Verbal feedback was considered nonaversive informational feedback, whereas aversive informational feedback was given by electric shock.

\section{Procedure}

The Ss were seated approximately $8 \mathrm{ft}$ directly in front of a projection screen on which faces of image size $32 \times 48$ in. were projected. The $E$ was positioned $5 \mathrm{ft}$ behind the $S$. All Ss received the following instructions: "The experiment in which you are participating concerns the ability to recognize faces. You will be presented four consecutive single faces for $2 \mathrm{sec}$ each with a 1-sec gap between each one. After the fourth face there will be a 60 -sec time lapse, after which you will be presented four consecutive sets of four faces each, each set of four being on the screen for 10 sec. In each set of four faces there will be one face which was seen just previously as one of the four single faces. In each set of four you must choose the face seen just previously. Before you there is a small panel with four buttons which form a square similar to the square formed by the four faces. You choose the one face in each set of four which you have seen just previously by pressing the button which is in the same position as that face. You have $10 \mathrm{sec}$ for each choice. Therefore, you must work quickly. This procedure will be repeated 25 times, until 100 single faces have been presented."

The Ss' choices were indicated on a light panel situated on the $E$ 's desk, allowing the $E$ to record the Ss' responses and to give feedback. Fifty Ss were trained on black faces, 50 on white faces. Twenty of each group were given electric shock feedback.
15 verbal feedback, and 15 no feedback. Assignment to groups was random within these restrictions. Ss were tested singly. In addition to the instructions above, the feedback groups were given the following instructions:

Shock feedback: "If you choose a face which you actually did not see before among the preceding four single faces you will receive a shock."

The S's nondominant hand was secured to an electric grid, the dominant hand being free for making the response. The $E$ delivered .4-mA shocks of $1 / 2-\mathrm{sec}$ duration to the $\mathrm{S}$, contingent upon incorrect responses. In a preexperimental check, this level of shock was found to be within the tolerance level of Ss. Ss in this group were informed that if they found the experimental situation aversive beyond their toleration they could leave the experiment without loss of credit. However, all Ss completed the experiment.

The verbal feedback group was told: "The E will say correct after each choice of a face which was actually one of the four single faces and wrong after incorrect choices, thus allowing you to know how you are doing."

The inspection faces (faces to be remembered) were chosen randomly, without replacement, from a pool of 100 faces. One hundred recognition displays were constructed, each containing four faces, one of which was one of the inspection faces. The other three (new faces) were chosen randomly, with replacement, from the same pool of 100 faces, with the following restrictions: (1) Each face appeared as a new face three times, but (2) appeared only once in a given block of 20 training stimuli, and (3) never appeared as a new face in the same block in which it served as an old or stimulus face. The order and position of faces was randomized within series. The order of the 25 series was the same for all $S_{3}$.

\section{Results and Discussion}

Analyses were carried out using both the number of correct responses and d' (Elliot, 1964). Since d' in a forced-choice test is a direct transformation of the percent correct score and their analyses in the present case yield nearly identical results, we shall present the analysis of $\mathrm{d}^{\prime}$ for consistency with other studies.

A three-factor analysis of variance (Race of Stimulus Face by Feedback Type by Training) with one repeated measure (training) was performed on $\mathrm{d}^{\prime}$. The 100 inspection faces were partitioned into five blocks of 20 , and $d^{\prime}$ was obtained for each block for each $S$. The means and standard deviations of correct responses and $d^{\prime}$ are given in Table 4 .

No significant main effect for race of stimulus was obtained $(F=3.34, d f=1,94)$. A main effect appeared for type of feedback, and no interactions with this factor were significant. Post hoc comparisons (Sheffé, 1959) showed shock feedback to be superior to no feedback, but verbal feedback, while intermediate, was not significantly different from either of the other types of training.

The interaction of race of stimulus face with amount of training was significant $(F=5.38$, df $=4,376$, $\mathrm{p}<.0005$ ) and is shown in Fig. 2. Tests of simple main effects for race of stimulus face at each level of training showed significantly better recognition of white over black faces within the first $(F=5.93, d f=1,94, p<.05)$ and fourth training blocks $(F=10.333, \mathrm{df}=1,94$, 
$p<.01)$. The reversal of means in the fifth training block was not significant. The main effect for training $(\mathrm{F}$ $=14.05, \mathrm{df}=4,376, \mathrm{p}<.00001)$ reflects the U-shaped relation of $\mathrm{d}^{\prime}$ scores over training anticipated as a function of interstimulus interference, as discussed above. Inspection of the standard deviations shown in Table 4 indicate that variability did not decrease with training.

The convergence of performance for black-trained and white-trained Ss suggests that training affected recognition of white faces and black faces differentially, such that initially significant differences were eliminated. One can only speculate on what would have happened if training had been carried further. Efforts to expand the stimulus set and investigate the course of training with more refined procedures seem justified.

\section{GENERAL DISCUSSION AND SUMMARY}

Of two experiments on training in face recognition, the first shows strong effects of verbal description training (up to $8 \mathrm{~h}$ of distributed training) on variables of verbal usage for faces, especially on communication accuracy, but no detectable effect of verbal description training on visual recognition. The second experiment, however, shows training effects in visual recognition after a relatively short training task ( $1 \mathrm{~h}$ at maximum). The two experiments differed in three ways: (1) the $\mathrm{Ss}^{\text {' }}$ response format, (2) the repetition of faces in the visual training experiment, and (3) the fact that training faces in the verbal study differed from the recognition test faces, whereas in the visual study the training and test faces were identical. Nevertheless, there appears to be no evidence that verbal processes of the kind investigated are important in face recognition.

Prior to training, there was no pattern of differential verbal usage by race of $S$ for differing stimulus race. The relationship between visual recognition and verbal labeling (especially communication accuracy) observed for color chips and for facial expressions could not be detected for faces of neutral expression. It is true that other studies have examined variation across perceptual objects, averaging responses across Ss, while the present work has grouped faces into difficult (other race) and easy (own race) categories in what is essentially an extreme groups design. It is possible that the differentiating characteristic of the race of the face interferes with the communication accuracy-recognition relationship, and that an extreme groups analysis applied to faces homogeneous by race would exhibit the communication accuracy-recognition relationship.

The second experiment shows a differential effect of training in visual recognition after a relatively short training task (less than $1 \mathrm{~h}$ ). While data from the second experiment was limited to white Ss, and there was no baseline with which to evaluate the effects of training on

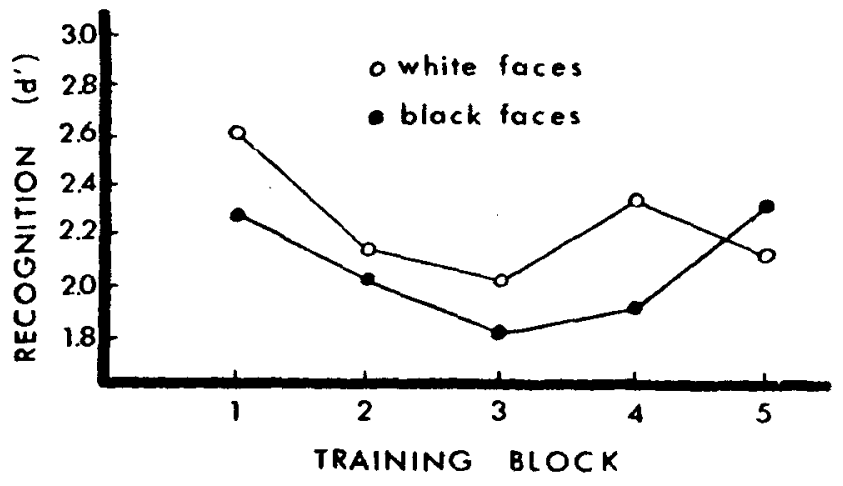

Fig. 2. Recognition performance ( $\left.d^{\prime}\right)$ for black and for white faces, over training.

white (own-race) faces, the differential effect of training on black as compared with white faces suggests that recognition for other-race faces can be improved by relatively simple and straightforward visual training.

\section{REFERENCES}

Banks, W. P. Signal detection theory and human memory. Psychological Bulletin, 1970, 74, 81-99.

Brown, R. W., \& Lenneberg, E. H. A study in language and cognition. Journal of Abnormal \& Social Psychology, 1954, $49,454-462$.

Cross, J. F., Cross, J., \& Daly, J. Sex, race, age and beauty as factors in recognition of faces. Perception \& Psychophysics, $1971,10,393-396$.

Elliott, P. B. Tables of d'. In J. A. Swets (Ed.), Signal detection and recognition in human observers. New York: Wiley, 1964.

Frijda, N., \& Van de Geer, J. P. Codability and recognition. Acta Psychologica, 1961, 18, 360-367.

Frost, N. Encoding and retrieval in visual memory tasks. Journal of Experimental Psychology, 1970, 85, 397-405.

Galper, R. E. Recognition of faces in photographic negative. Psychonomic Science, 1970, 19, 207-208.

Galper, R. E., \& Hochberg, J. Recognition memory for photographs of faces. American Journal of Psychology, 1971, 84, 351-354.

Gass, M. A. Differential recognition of black and white faces. Unpublished BS thesis, University of Illinois, 1972.

Goldstein, A. G., \& Chance, J. E. Visual recognition memory for complex configurations. Perception \& Psychophysics, 1970, 9, 237-241.

Herskovitz, M. The anthropometry of the American Negro. New York: Columbia University Press, 1930.

Hochberg, J., \& Galper, R. E. Recognition for faces: I. An exploratory study. Psychonomic Science, 1967, 9, 619-620.

Lantz, D., \& Stefflre, V. Language and cognition revisited. Journal of Abnormal \& Social Psychology, 1964, 69, 472-481.

Malpass, R. S., \& Kravitz, J. Recognition for faces of own and other "race." Journal of Personality \& Social Psychology, $1969,13,330-335$.

Palmer, R. J., \& Masling, J. Vocabulary for skin color in Negro and white children. Developmental Psychology, 1969. 1. 396-401.

Sheffé, H. The analysis of variance. New York: Wiley, 1959. 
Smith, E. E., \& Nielsen, G. D. Representations and retrieval processes in short term memory: Recognition and recall of faces. Journal of Experimental Psychology, 1970, 85, $397-405$.

Tversky, B. Pictorial and verbal encoding in a short term memory task. Perception \& Psychophysics, 1969, 6, 225-233.

Yin, R. K. Looking at upside-down faces. Journal of Experimental Psychology, 1969, 81, 141-145.

\section{NOTES}

1. "Race" in the context of this study is merely a shorthand way of referring to differences in physiognomy that correlate with and serve as cues to the socially designated race of the $S$ or stimulus person. "Race" is thus treated as a folk concept, not a technical term.

2. Documentation of black-white differences in physical features is presented in Herskovitz $(1930)$, and specifically for a sample of the faces used in the present research by Gass (1972).

3. Summaries of the canonical correlation analysis are available from the authors.

(Received for publication December 11, 1972; revision received March 11, 1973.) 